\title{
Studies on Phenolic Steroids in Human Subjects
}

\author{
IX. ROLE OF THE INTESTINE IN THE \\ CONJUGATION OF ESTRIOL
}

\author{
N. Inoue, A. A. Sandberg, J. B. Graham, and W. R. Slaunwhite, Jr. \\ From The Roswell Park Memorial Institute and The Medical Foundation of \\ Buffalo, Buffalo, New York 14203
}

A B S T R A C T In order to compare the enteric circulation of estriol-16 $\alpha$-glucosiduronate (see preceding paper) with that of estriol $\left(E_{s}\right)$, labeled estriol was administered to six women by several routes: both injection and infusion (300 $\mathrm{min}$ ) into the cubital vein, injection into the portal vein system, ingestion and instillation into the jejunum and ileum. Urine, collected from $0-2,2-4,4-8,8-12$, and $12-24 \mathrm{hr}$, was analyzed by countercurrent distribution for its content of radioactive 3 - and 16-glucosiduronate ( $\left.\mathrm{E}_{s}-3 \mathrm{Gl}, \mathrm{E}_{s}-16 \mathrm{Gl}\right)$ and sulfoglucosiduronate ( $\left.\mathrm{E}_{s}-3 \mathrm{~S}, 16 \mathrm{Gl}\right)$ of estriol. After peripheral injection of $E_{s}, E_{s}-16 G l$ was excreted rapidly and $E_{3}-3 S, 16 \mathrm{Gl}$ at a slower and more constant rate. Es-3Gl was barely detectable after infusion. After injection of $E_{3}$ into the portal vein, the excretion of $E_{s}-3 S$, $16 \mathrm{Gl}$ was greater and quicker than after peripheral injection. Even in a subject with a complete bile fistula, the urinary excretion of $\mathrm{E}_{s}-3 \mathrm{~S}, 16 \mathrm{Gl}$ was essentially unchanged. Ingestion also produced the same result. Only after instillation into the ileum was a large and rapid excretion of $E_{3}-3 G 1$ obtained, whereas the excretion of $\mathrm{E}_{s}-3 \mathrm{~S}, 16 \mathrm{Gl}$, and $\mathrm{E}_{3}-16 \mathrm{Gl}$ were depressed. These results together with those of the preceding paper suggest that $\mathrm{E}_{3}$ does not readily appear in the small intestine except via a hepatoenteric circulation that produces very little $\mathrm{E}_{3}-3 \mathrm{Gl}$. When present in the distal segment of the small intestine, however, absorption, conjugation, and elimination proceed readily.

\section{INTRODUCTION}

In a previous communication (1) we showed that the metabolic fate of labeled estriol $16 \alpha$-glucosiduronate ${ }^{1}$

Dr. Inoue is a postdoctoral fellow from the 1st Medical Clinic, Faculty of Medicine, University of Tokyo, Japan.

Received for publication 24 June 1968 and in revised form 18 September 1968.

${ }^{1}$ The following abbreviations and trivial names are used: estriol $\left(E_{3}\right)$, estra-1,3,5(10)-triene-3,16 $\alpha, 17 \beta$-triol; estriol$16 \alpha$-glucosiduronate $\left(\mathrm{E}_{3}-16 \mathrm{G} 1\right), 3,17 \beta$-dihydroxyestra-1,3,5- was affected by its route of administration. Continuous, prolonged infusion as opposed to a rapid, single injection yielded a 3-glucosiduronate of estriol after a lag period of several hours (2). In order to explain such a lag period, it is necessary to postulate a pool which does not equilibrate readily with the pool in the vascular circulation. One possibility is an enteric circulation via the succus entericus (1), together with the formation of $\mathrm{E}_{3}-3 \mathrm{Gl}$ in the intestine, as has recently been shown by Stoa and Levitz (3). Since a role of the enterohepatic circulation is ruled out by the failure of the labeled steroid conjugate to appear in appreciable amounts in the bile, the experimental results were in accord with this postulate. Doubly labeled esteriol $16 \alpha$-glucosiduronate injected into the intestinal lumen appeared, after a characteristic and consistent delay, in the urine as both the 3- and 16-conjugate of estriol, labeled primarily in the estriol moiety. Thus, absorption from the small intestine into the circulation and subsequent excretion in the urine apparently require prior hydrolysis. Whether the conjugate appears in the intestine, by passive or active means, has yet to be verified experimentally. To establish this, it became imperative to inject estriol in a fashion analagous to that of $E_{3}-16 \mathrm{Gl}$.

\section{METHODS}

$\mathrm{E}_{3}-6,7-{ }^{8} \mathrm{H}(140 \mu \mathrm{c} / \mu \mathrm{mole})^{2}$ or $\mathrm{E}_{3}-16-{ }^{14} \mathrm{C}(6.3 \mu \mathrm{c} / \mu \mathrm{mole})^{3}$ was administered to six women: three normal women in the (10)-trien-16 $\alpha$-yl- $\beta$-D-gluco pyranosiduronate; estriol-3-glucosiduronate $\quad\left(E_{3}-3 \mathrm{G} 1\right), 16 \alpha, 17 \beta$-dihydroxyestra-1,3,5 (10)trien-3-yl- $\beta$-D-glucopyranosiduronate; estriol-3-sulfate-16 $\alpha$ glucosiduronate $\left(\mathrm{E}_{3}-3 \mathrm{~S}, 16 \mathrm{G} 1\right)$, 3-sulfo-17 $\beta$-hydroxyestra-1,3,$5(10)$-trien-16 $\alpha$-yl- $\beta$-D glucopyranosiduronate ; estriol-3,-16 $\alpha-$ diglucosiduronate $\left(\mathrm{E}_{3}-3,16 \mathrm{Gl}\right)$, estriol-3,16 $\alpha$-bis-(-D-glucopyranosiduronate); estriol-3-sulfate $\left(E_{3}-3 S\right), 16 \alpha-17 \beta$-dihydroxyestra-1,3,5(10)-trien-3-yl sulfate: UDPGA, uridine diphospho glucuronic acid; CCD, countercurrent distribution.

${ }_{2}$ The $E_{3}-6,7-{ }^{8} \mathrm{H}$ was purchased from New England Nuclear Corporation.

${ }^{3}$ The $\mathrm{E}_{3}-16-{ }^{14} \mathrm{C}$ was synthesized by Dr. Mortimer Levitz from whom it was obtained through the courtesy of the American Cancer Society. 
TABLE I

Route of Administration and Amount of $E_{3}-6,7-{ }^{3} \mathrm{H}$ or $E_{3}-16-{ }^{14} \mathrm{C}$ Administered to Female Subjects

\begin{tabular}{cclcl}
\hline Subject & Age & \multicolumn{1}{c}{ Route of administration } & $\begin{array}{c}\text { Radioactivity } \\
\text { administered }\end{array}$ & Diagnosis \\
\hline $1^{*}$ & 43 & Cubital vein & $1 \mu \mathrm{c}{ }^{14} \mathrm{C}$ & Normal \\
2 & 28 & Cont. infusion into cubital vein & $10 \mu \mathrm{c}{ }^{3} \mathrm{H}$ & Normal \\
3 & 48 & Portal vein & $1 \mu \mathrm{c}{ }^{14} \mathrm{C}$ & Uterine carcinoma \\
$4^{*}$ & 43 & Ingestion & $10 \mu \mathrm{c}{ }^{3} \mathrm{H}$ & Normal \\
5 & 55 & Cubital vein & $50 \mu \mathrm{c}{ }^{3} \mathrm{H}$ & Biliary fistula (T-tube) \\
6 & 48 & Terminal ileum & $10 \mu \mathrm{c}{ }^{3} \mathrm{H}$ & Uterine carcinoma \\
\hline
\end{tabular}

* Same subject.

follicular phase of the menstrual cycle, two with carcinoma of uterus at abdominal operation, and one with a biliary fistula ( $T$-tube drainage). All subjects were in good nutritional status, and none had evident renal or hepatic dysfunction. The route of administration and other data related to these subjects are shown in Table I. The steroids administered were shown to be pure by paper chromatography.

The method of injection, the collection of urine, the extraction of urinary conjugates, the measurement of radioactivity, the solvent systems employed in CCD, and the partition coefficients of estriol conjugates in these systems (Table II) were exactly as those described in our previous paper (1). The ethanol extracts of the urine were submitted to CCD for 49 transfers in solvent system A (1). About 35 $\mathrm{mg}$ of sodium sulfate were added to tubes 0 and 1 in order to suppress emulsification of the phases. Two or three fractions were obtained, i.e., fraction $I(N=5-7$, where $N$ is the peak tube), fraction II $(\mathrm{N}=10-11)$, and fraction III ( $N$ $=31-33)$. The first two fractions were redistributed in the same solvent system for 99 or 299 transfers and fraction III for 99 transfers in solvent system $C$. The partition coefficients and percentage of compounds present in the CCD train were computed by means of a computer program developed by Priore and Kirdani $(4,5)$. The percentage of the $E_{3}$ conjugates was calculated on the basis of the radioactivity present in each peak of the first CCD run. The urinary and biliary metabolites were characterized according to techniques described in our previous paper (1).

\section{RESULTS}

Injection into the cubital vein. The cumulative radioactivity of urinary conjugates during the 1 st $24 \mathrm{hr}$ after injection or continuous infusion of $\mathrm{E}_{s}$ into two normal women in the follicular phase of the menstrual cycle is shown in Fig. 1.

After a single, rapid injection, the excretion pattern of the urinary radioactivity was identical with that of our previous report (6), i.e., approximately $30 \%$ of the radioactivity injected was excreted within $4 \mathrm{hr}$ and nearly $50 \%$ within $8 \mathrm{hr}$. The preponderant portion of the urinary radioactivity was excreted as $E_{s}-16 \mathrm{Gl}$; about $14 \%$ of the radioactivity administered was excreted in the urine as $E_{3}-3 \mathrm{~S}, 16 \mathrm{Gl}$. In the case of the continuous infusion for $300 \mathrm{~min}$, the excretion patterns of the total radioactivity, $\mathrm{E}_{3}-16 \mathrm{Gl}$ and $\mathrm{E}_{3}-3 \mathrm{~S}, 16 \mathrm{Gl}$ were almost identical with those obtained after the single injection. A small amount of $\mathrm{E}_{3}-3 \mathrm{Gl}$, however, was found in the urine starting $8 \mathrm{hr}$ after cessation of infusion. Since less than $2 \%$ of the urinary radioactivity was present as this conjugate, its identification should be regarded with caution. In both experiments, it appears that the excretion of $\mathrm{E}_{3}-3 \mathrm{~S}, 16 \mathrm{Gl}$ was at a relatively constant rate, whereas that of $\mathrm{E}_{3}-16 \mathrm{Gl}$ was at least at a double rate, i.e., an initial rapid rate followed by a subsequently slower one. Therefore, the relative amount of $\mathrm{E}_{3}-3 \mathrm{~S}$, $16 \mathrm{Gl}$ as compared to $\mathrm{E}_{3}-16 \mathrm{Gl}$ increased gradually with the passage of time.

The results obtained by analysis of conjugation of the urine show only the net effect of many processes in different metabolic pools. Since such pools may exist in the enteric or enterohepatic circulation, it is important to investigate whether these pools do exist and the characteristic of each pool in the disposition of the $E_{s}$ or $\mathrm{E}_{3}$ conjugates. On the assumption that these pools might exist in the liver and/or in the small intestine (including the lumen), the following experiments were undertaken.

Injection in to the portal vein system. In order to assess the role of the liver in the disposition of $E_{s}$, the steroid was injected directly into the portal vein system. Considerable amounts of Es-3S,16G1 were excreted

TABLE II

Partition Coefficients of Some Estriol Conjugates

\begin{tabular}{lccc}
\hline Conjugate & System A & System B & System C \\
\hline $\mathrm{E}_{3}-16 \mathrm{Gl}$ & 2.1 & 1.1 & 0.7 \\
$\mathrm{E}_{3}-3 \mathrm{Gl}$ & 0.21 & 0.1 & 0.7 \\
$\mathrm{E}_{3}-3 \mathrm{~S}, 16 \mathrm{Gl}$ & 0.09 & 0.05 & 0.1 \\
$\mathrm{E}_{3}-3 \mathrm{~S}$ & 4.1 & 1.9 & 4.8 \\
\hline
\end{tabular}

System $\mathrm{A}=n$-butanol :ethylacetate $: 0.2 \%$ ammonium hydroxide $(3: 1: 4)$; System $\mathrm{B}=n$-butanol :ethylacetate $: 0.2 \%$ ammonium hydroxide $(1: 1: 2)$; System $\mathrm{C}=n$-butanol:10\% ammonium hydroxide (1:1). 


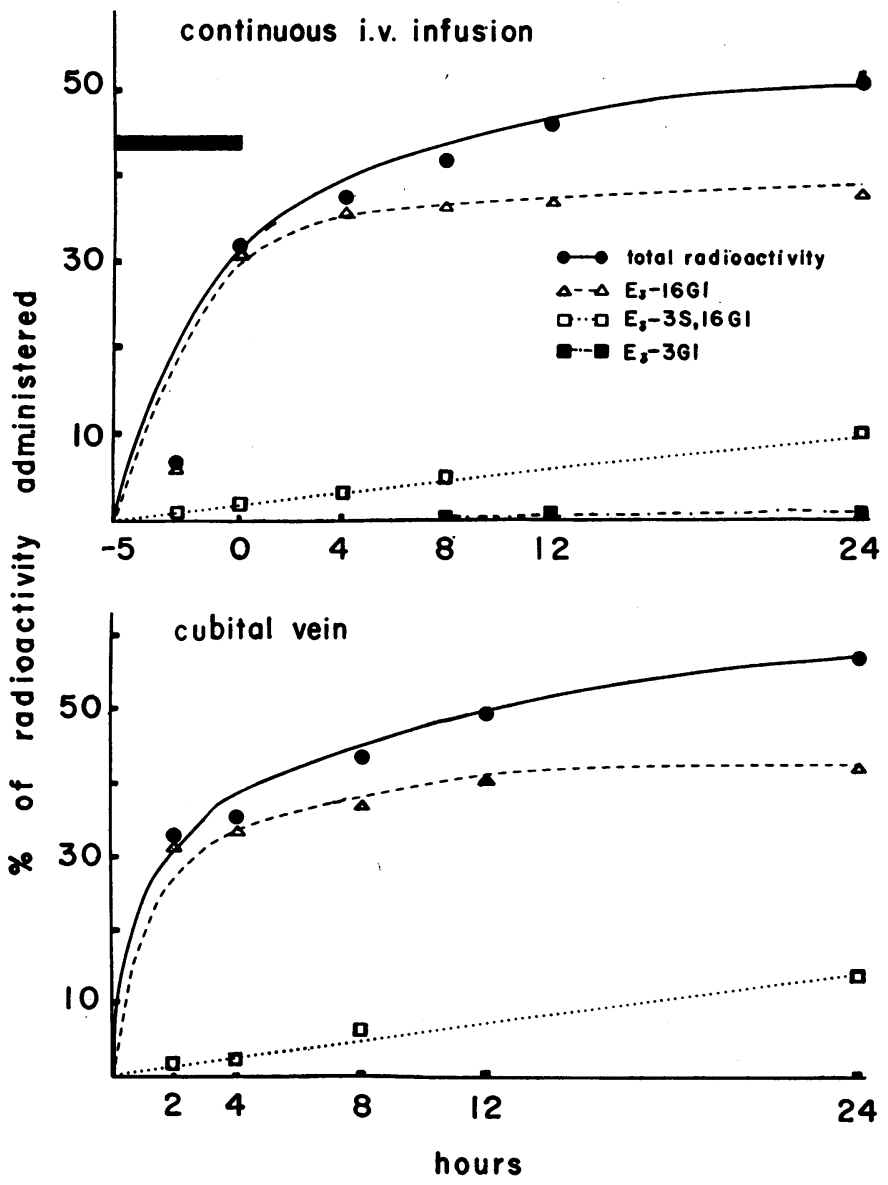

FIGURE 1 The cumulative urinary excretion of radioactive estriol conjugates following a $300 \mathrm{~min}$ (solid bar) infusion (TOP) and following the rapid injection (BOTTOM) into peripheral veins of two normal women of $10 \mu \mathrm{c}$ of $6,7-{ }^{8} \mathrm{H}$-estriol and of $1 \mu \mathrm{c}$ of $16-{ }^{14} \mathrm{C}-$ estriol, respectively. As was pointed out in the previous paper, even though the lines in this and in the following figures have been extrapolated to 0 , the segment between $0-2 \mathrm{hr}$ has no meaning regarding the rate of excretion of radioactivity during that period. immediately in the urine (Fig. 2). The percentage of $\mathrm{E}_{\mathrm{s}}-3 \mathrm{~S}, 16 \mathrm{Gl}$ excreted in the urine during $0-4 \mathrm{hr}$ after injection into the portal vein was much higher than that obtained after a single injection into the cubital vein $(9.12 \%$ vs. $5.5 \%)$. Thereafter, the proportion of $\mathrm{E}_{3}-3 \mathrm{~S}, 16 \mathrm{Gl}$ to $\mathrm{E}_{3}-16 \mathrm{Gl}$ increased gradually in the same manner as that following injection into the cubital vein. No $\mathrm{E}_{3}-3 \mathrm{Gl}$ or $\mathrm{E}_{3}-3 \mathrm{~S}$ was detected.

Peripheral injection into a subject with T-tube drainage of bile. In order to further clarify the hepatic disposition of $E_{s}$, the steroid was injected into a subject with a T-tube, whose bile was continuously drained during the time of the study so that no enterohepatic circulation could occur. After injection into the cubital vein (Fig. 2), nearly $30 \%$ of the radioactivity administered was excreted in the urine within $24 \mathrm{hr}$; approximately $20 \%$ was excreted in the bile." Nearly $8 \%$ of the radioactivity injected was excreted in the urine as $\mathrm{E}_{3}-3 \mathrm{~S}$, $16 \mathrm{Gl}$, whereas after intraportal injection about $11 \%$ was

4 This bile and an aliquot of this urine was analyzed and reported separately by Kirdani, Priore, and Sandberg (23). A sepecially constructed $\mathrm{T}$-tube assured complete collections of bile. present as this conjugate. These amounts are also comparable with those obtained after injection into the cubital vein, 10.6 and $14.0 \%$ for single injection and continuous infusion, respectively. No detectable amounts of $\mathrm{E}_{s}-3 \mathrm{Gl}$ and $\mathrm{E}_{3}-3 \mathrm{~S}$ were excreted in the urine.

In summary, under experimental conditions in which the results should reflect hepatic disposition, the urine contained mostly $E_{s}-16 \mathrm{Gl}$ and some $\mathrm{E}_{s}-3 \mathrm{~S}, 16 \mathrm{Gl}$. The rate

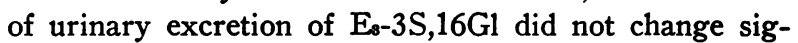
nificantly with or without enterohepatic circulation. No detectable amount of $\mathrm{E}_{\mathrm{s}-3 \mathrm{Gl}}$ was excreted in the urine.

Ingestion. The findings that a small amount of $E_{s-3 G l}$ may have been present in the urine after the infusion of $E_{3}$ for a 300 min period and that hepatic disposition does not appear to be concerned with $\mathrm{E}_{8}-3 \mathrm{Gl}$ formation led us to study the enteric disposition of $E_{\text {s. }}$.

In order to know the net effect on the urinary $E_{s}$ conjugates formed during passage through the gut, liver, and kidneys, $\mathrm{E}_{s}$ was administered orally. The results are shown in Fig. 3. Approximately $30 \%$ of the radioactivity administered was excreted in the urine during the initial $24 \mathrm{hr}$ after ingestion. The preponderant part of the radioactivity was excreted as $\mathrm{E}_{s}-16 \mathrm{Gl}$; $\mathrm{E}_{s}-3 \mathrm{~S}, 16 \mathrm{Gl}$ 


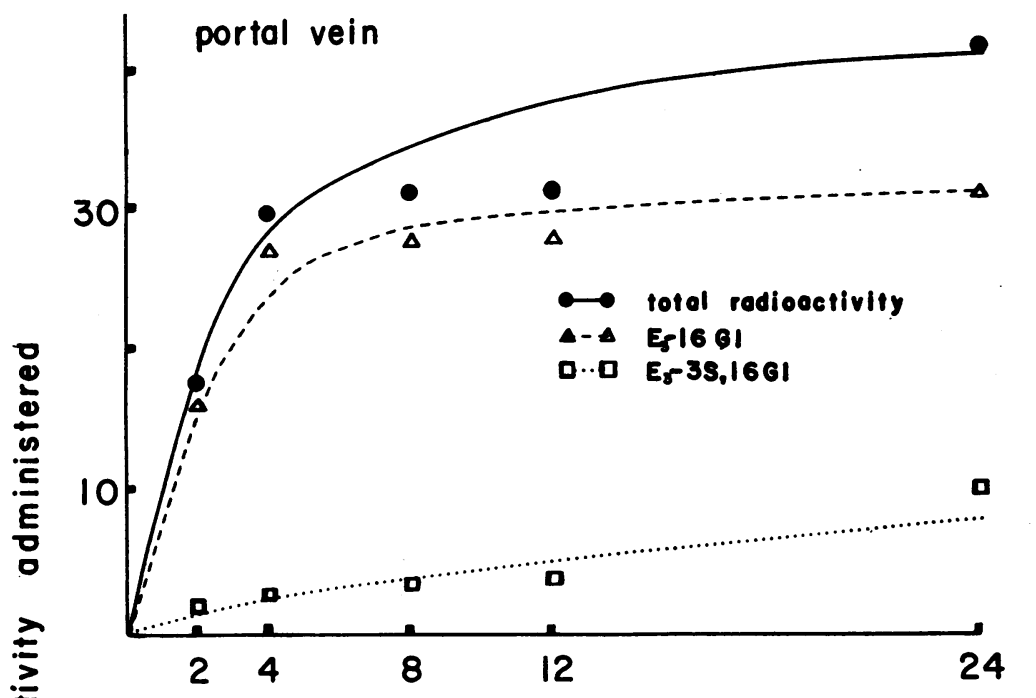

Figure 2 The cumulative urinary excretion of radioactive estriol conjugates following injection of $1 \mu \mathrm{c}$ of $16-{ }^{14} \mathrm{C}$-estriol into the portal vein system of a woman with uterine carcinoma (TOP) and following peripheral injection of $50 \mu \mathrm{C}$ of $6,7-{ }^{8} \mathrm{H}$-estriol into a woman with a complete biliary fistula (BOTTOM).

\section{hours}

appeared in the urine in the first period ( $0-2 \mathrm{hr})$. The proportion of Es-3S,16Gl to E-16Gl increased gradually with time. No detectable amount of $\mathrm{E}_{8}-3 \mathrm{Gl}$ was excreted in the urine, indicating that $\mathrm{E}_{\mathrm{s}}-3 \mathrm{Gl}$ was not formed at that part of the gastrointestinal tract where the steroid was absorbed, not in the liver or in the kidney.

Instillation into the terminal ileum. Another approach to determine the site of $\mathrm{E}_{\mathrm{s}}-3 \mathrm{Gl}$ formation was made by injecting $E_{s}$ into the terminal ileum at abdominal operation. During the $24 \mathrm{hr}$ after injection of $E_{s}$, the rates and patterns of urinary excretion of total radioactivity and various conjugates were considerably different from those obtained after administration of $E_{\text {s }}$ by other routes (Fig. 3). The rapid excretion of $E_{s-3 G 1}$ was the most characteristic feature ; almost equal amounts of $\mathrm{E}_{s-16 \mathrm{Gl}}$ were excreted in the urine, whereas $\mathrm{E}_{s-3 \mathrm{~S}}$, $16 \mathrm{Gl}$ constituted only $6.4 \%$.

Characterization of the urinary estriol conjugates. Primary identification was based on partition coeffi- cients in two solvent systems. Previous experience (1) combined with better methods of quantitation of CCD $(4,5)$ have increased our confidence in the methodology. As a result, only the $E_{s-3 S, 16 G l}$ fractions from all the experiments were combined and treated further as previously described (1). In summary, Es-3S,16Gl moved identically with authentic standard ${ }^{5}$ in CCD $(\mathrm{N}=299)$, in high voltage paper electrophoresis, and on paper chromatography. Partial and sequential enzymatic ${ }^{\circ}{ }^{7}$ hydrolyses yielded products consistent with the assignment made. Thus our confidence appears to be justified.

\section{DISCUSSION}

Recent tracer studies on the fate of $E_{s}$ in normal or pregnant women revealed that whereas no significant

${ }^{5}$ The $\mathrm{E}_{8}-15-{ }^{8} \mathrm{H}-3 \mathrm{~S}, 16 \mathrm{Gl}$ was kindly supplied by Dr. $\mathrm{M}$. Levitz (22).

- Sigma Chemical Co., Bacterial Type II.

${ }^{7}$ Mann Research Lab, Asperigillus oryzae. 

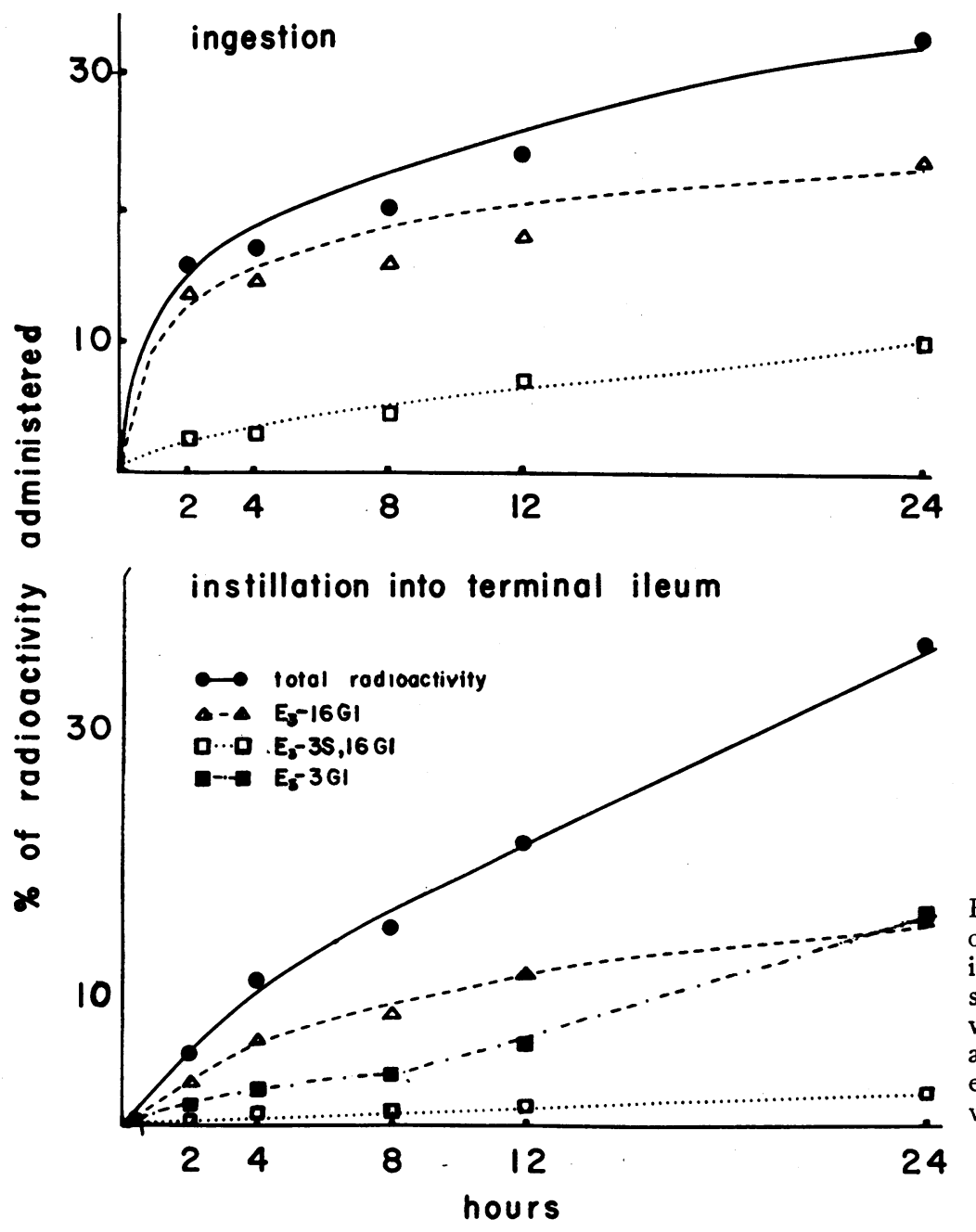

Figure 3 The cumulative urinary excretion of radioactive estriol conjugates following ingestion of $10 \mu \mathrm{c}$ of $6,7-{ }^{8} \mathrm{H}$-estriol by the same subject who received the rapid intravenous injection (see Fig. 1, bottom) (TOP) and following instillation of $10 \mu \mathrm{c}$ of $6,7-{ }^{8} \mathrm{H}$ estriol into the terminal ileum of a woman with uterine carcinoma (BOTTOM).

metabolic alteration of the steroid molecule itself occurs $(6,7), E_{3}$ conjugates exist which can undergo reand transconjugation $(2,8)$. None except Es-16Gl $(9)$, has been isolated and identified in chemically pure form. Of these $E_{3}$ conjugates, it has been shown that $E_{3}-16 \mathrm{Gl}$, the major urinary metabolite of estriol, is formed efficiently by human liver (10) and human small intestine $(11,12)$, whereas $\mathrm{E}_{s}-3 \mathrm{~S}, 16 \mathrm{Gl}$, the major biliary metabolite of estriol (13), is presumably made in the liver. The interesting observation that significant amounts of $E_{s}-3 G 1$ are excreted in the urine after infusion of either $E_{s}$ or $E_{3}-16 G 1$ into normal or pregnant women has recently been presented $(1,2,14)$. $\mathrm{E}_{\mathrm{s}}-3 \mathrm{Gl}$ is also an important constituent of pregnancy urine $(15,16)$. The enzyme responsible for 3-glucuronide formation is located in some part of the small intestine $(12,17)$. Stoa and Levitz (3) have convincingly demonstrated that $\mathrm{E}_{3}-3 \mathrm{Gl}$ is an intestinal metabolite of estriol in vivo.

The present study was designed to estimate primarily the role of the liver and of the gastrointestinal tract in the conjugation of estriol in vivo. After the direct injection of $E_{s}$ into the portal vein, so that practically all of the steroid passes directly through the liver, Es-3S, $16 \mathrm{Gl}$ and $\mathrm{E}_{\mathrm{s}}-16 \mathrm{Gl}$ were immediately excreted in the urine in a slightly higher ratio than that ratio obtained from peripheral administration. The fact that the urinary excretion of $E_{3}-3 \mathrm{~S}, 16 \mathrm{Gl}$ continued for at least 24 $\mathrm{hr}$ at a relatively constant rate, whereas the amount of $\mathrm{E}_{3}-16 \mathrm{Gl}$ in the urine decreased with time, may indicate that a small portion of the $\mathrm{E}_{s}$ or $\mathrm{E}_{s}-16 \mathrm{Gl}$ was retained in the liver for a longer period of time. It was then excreted in the urine as well as in the bile as $\mathrm{E}_{s}-3 \mathrm{~S}, 16 \mathrm{Gl}$ in confirmation of the results of Stoa and Levitz (3). Another possibility is the enterohepatic circulation of $\mathrm{E}_{3}-3 \mathrm{~S}, 16 \mathrm{Gl}$, which is known to be the major estriol conjugate in bile (13). However, the comparable amounts of $\mathrm{E}_{\mathrm{s}}-3 \mathrm{~S}$, $16 \mathrm{Gl}$ excreted in the urine after injection of $\mathrm{E}_{3}$ into a patient with complete bile collection would favor the 
former possibility. These findings are in accord with those of Emerman Twombly, and Levitz (13), who observed that, following the intravenous infusion of $E_{s}-3 S$ into patients whose bile was continuously drained via a T-tube, only $\mathrm{E}_{\mathrm{s}}-16 \mathrm{Gl}$ and $\mathrm{E}_{\mathrm{s}}-3 \mathrm{~S}, 16 \mathrm{Gl}$ were excreted in the urine.

Another approach to the study of the hepatic metabolism of $\mathrm{E}_{3}$ was made by ingestion. Although this experiment was probably unphysiological and the urinary recovery of radioactivity was poor, it is interesting that the urine contained $\mathrm{E}_{s}-16 \mathrm{Gl}$ and $\mathrm{E}_{s}-3 \mathrm{~S}, 16 \mathrm{Gl}$ in almost the same relative amounts as those obtained after injection into the portal vein. Thus, it appears most likely that most of the $E_{s}-16 G 1$ and all of the $E_{s}-3 S, 16 G 1$ are formed by the liver and excreted in the urine. The amount of urinary $\mathrm{F}_{3}-3 \mathrm{~S}, 16 \mathrm{Gl}$ is small and may or may not be related to that involved in the enterohepatic circulation. Most striking was the constancy of urinary excretion of

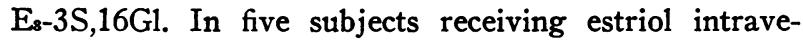
nously, including one with complete bile collection,, $\mathrm{E}_{s-}$ $3 \mathrm{~S}, 16 \mathrm{Gl}$ excretion averaged $26 \%$ (range $21-29 \%$ ) of the urinary radioactivity. (In contrast, this value was $6 \%$ with injection into the ileum.)

No remarkable difference between the results obtained after single injection and continuous infusion of $\mathrm{E}_{3}$ was observed. This is in marked contrast to the results with $\mathrm{E}_{\mathrm{s}-16 \mathrm{Gl}}$ (1) and indicates a difference in the handling of the two molecules. There are at least two alternative explanations. First, Es does not participate in an enteric circulation because its hepatic clearance may be more rapid than that of $\mathrm{E}_{3}-16 \mathrm{Gl}$, thus giving the latter more opportunity to diffuse across the intestinal wall. Alternatively, there may be a specific structural requirement that tends to transport the conjugate across intestinal membranes more rapidly than its aglycone. This does not necessarily imply active transport since there is a difference in charge.

Our failure (see Fig. 1) to detect $\mathrm{E}_{3}-3 \mathrm{G} 1$ in the urine of subjects given intravenous $E_{s}$ is in contrast to the results of Goebelsmann, Sjoberg, Wiquist, and Diczfalusy (2) in which a considerable amount of $E_{3}-3 G 1$ (10\%) was excreted in the urine during $24 \mathrm{hr}$ after infusion of $E_{s}$. There is no apparent reason that can readily account for this discrepancy, but it may be related to a remarkable viariability exhibited by different subjects in the metabolism of $E_{s}$, to differences in intestinal flora of the patients, or to differences in amounts of metabolites excreted in the bile and/or succus entericus. Substantial variations in the excretion of estriol or its conjugates have been reported, e.g., the failure of Levitz and Katz (8) to detect $\mathrm{E}_{s}-3 \mathrm{~S}, 16 \mathrm{Gl}$ in the urine of their subjects after injection of the double conjugate into the duodenum, the impressively low conversion of intraduodenally instilled $\mathrm{E}_{s}$ to $\mathrm{E}_{3}-3 \mathrm{Gl}$ reported by Stoa and Levitz (3), and the differences in the biliary excretion of $E_{3}$ or its conjugates $(6,13)$. Thus, it is possible, though not likely, that none of our subjects excreted significant amounts of the injected $E_{3}$ into the bile, even though the excretion of significant amounts of $E_{s}-3 \mathrm{~S}$, $16 \mathrm{Gl}$ in the urine indicates that the subjects were capable of forming the major conjugated metabolite of $\mathrm{E}_{3}$ excreted under normal concentrations in the bile. It is also possible that substantial amounts of $E_{3}$ were excreted in the bile, but that the subjects' intestinal tract was lacking in the enzyme system necessary for hydrolysis of the $E_{s}$-conjugates and reconjugation at position-3. Even though any of the above speculations may explain the discrepancies between our results and those of others, we are, nevertheless, perplexed by our failure to find $E_{s}-3 G$ l following the intravenous administration of $E_{s}$, since a substantial biliary excretion of $E_{s}$ (about $20 \%$ ) has been adequately demonstrated (6), in contrast to the seeming lack of such excretion after the administration of $\mathrm{E}_{s}-16 \mathrm{Gl}$. Yet, the 3-glucuronide was observed in the urine of subjects given the latter but not the former compound. It is hoped that future studies will shed light on this complex picture.

$E_{s}$ conjugates usually remain intact in the upper part of the small intestine (11) although low glucuronidase activity in the bile has been observed (18). Assuming that reabsorption of $\mathrm{E}_{s}$ or $\mathrm{E}_{s}$ conjugates is a passive process, $\mathrm{E}_{3}-3 \mathrm{~S}, 16 \mathrm{Gl}$, which is an extremely water-soluble compound of larger molecular size $^{8}$ than the effective pore radius of the mucosal membrane (3A-6.5A) (19), is not easily reabsorbed. Free $E_{s}$, however, may be absorbed by diffusion through the lipoidal face of the mucosa in the same manner as cortisol or progesterone (20, $21)$. Therefore, even though the biliary $\mathrm{E}_{\mathrm{s}}-3 \mathrm{~S}, 16 \mathrm{Gl}$ may be absorbed to a variable extent in the upper small intestine, it is more likely that it reaches the terminal ileum where it is hydrolyzed, probably under the influence of bacterial flora, and reconjugated. The finding that a considerable amount of $\mathrm{E}_{s}-3 \mathrm{Gl}(16 \%)$ (Fig. 3) was excreted in the urine after injection of $E_{3}$ into the terminal ileum is in accord with this view.

However, rates and patterns of urinary excretion of the total radioactivity and $\mathrm{E}_{s}-3 \mathrm{Gl}$ after injection of $\mathrm{E}_{s}$ into the terminal ileum were so different from those obtained from other routes of administration that this is probably not the major physiological route of estriol metabolism. In addition, the results obtained from in vitro experiments in our laboratory showed that the upper small intestine mostly formed $\mathrm{E}_{3}-16 \mathrm{Gl}$ and the lower small intestine formed $\mathrm{E}_{3}-16 \mathrm{Gl}$ and $\mathrm{E}_{3}-3 \mathrm{Gl}$ in relative amounts of 2.5:1 (Table III). Therefore, it may be

\footnotetext{
${ }^{8}$ Estriol occupies a space roughly equivalent to a cylinder $6 \mathrm{~A}$ in diameter by $13 \mathrm{~A}$ long (24). A model of $\mathrm{E}_{3}-3 \mathrm{~S}, 16 \mathrm{G} 1$ shows that the carbohydrate moiety attached to the $\mathrm{C} 16 \alpha$ oxygen can fit under the $\alpha$-surface of the steroid, thereby more than doubling its diameter.
} 
TABLE III

$E_{3}$ Conjugates Formed by Different Parts of the Human Small Intestine*

\begin{tabular}{lccccccc}
\hline & & & \multicolumn{4}{c}{ Per cent of conjugate formed } \\
\cline { 3 - 7 } & & $\begin{array}{c}\text { No. of } \\
\text { cases }\end{array}$ & $\begin{array}{c}\text { Per cent } \\
\text { conjugation }\end{array}$ & E $_{3-16 G 1}$ & E $_{8-3 G 1}$ & E $_{3-3 S}$ & $\begin{array}{c}\text { E }_{3-} \\
\text { double } \\
\text { conju- } \\
\text { gate }\end{array}$ \\
\hline Jejunum & 2 & 87.2 & 88.2 & 7.3 & 4.6 & \\
Ileum & 6 & 59.6 & 63.4 & 26.5 & 4.4 & 2.9 \\
\hline
\end{tabular}

* All incubations were performed for $1 \mathrm{hr}$ in $3.0 \mathrm{ml}$ of $0.1 \mathrm{M}$ phosphate buffer, $\mathrm{pH} 7.3$, containing $100 \mathrm{mg}$ of the mucosa homogenized in 10 volumes of phosphate buffer, $50 \mu \mathrm{g}$ of $\mathrm{E}_{2}, 0.5 \mu \mathrm{g}$ of $\mathrm{E}_{8}-6,7-{ }^{2} \mathrm{H}$, and $200 \mu \mathrm{g}$ of UDPGA. The amounts of the $\mathrm{E}_{3}$ conjugates formed are shown as their relative amounts after CCD.

$\ddagger$ Due to the small amount of this very polar conjugate, rigorous identification could not be made.

plausible to presume that the lower portion of the small intestine is the most probable site of $\mathrm{E}_{\mathrm{s}}-3 \mathrm{Gl}$ formation.

On the basis of our present study and the data available in the literature, particularly the recently published results and concepts formulated by Stoa and Levitz (3), our suggestion for the fate of $\mathrm{E}_{3}$ can be formulated as follows: (a) Most of the circulating $\mathrm{E}_{3}$ is extracted by the liver and converted to $\mathrm{E}_{8}-16 \mathrm{Gl}$ and $\mathrm{E}_{3}-3 \mathrm{~S}, 16 \mathrm{Gl}$. (b) Nearly all of the $\mathrm{E}_{s}-16 \mathrm{Gl}$ is released into the blood stream and most of it is excreted in the urine, but some enters the small intestine possibly via the succus entericus. (c) $\mathrm{E}_{3}-3 \mathrm{~S}, 16 \mathrm{Gl}$ is excreted in the bile where it is the major conjugate of estriol. $(d)$ In the intestine, part of the biliary $\mathrm{E}_{\mathrm{s}}-3 \mathrm{~S}, 16 \mathrm{Gl}$ may be transported intact through the mucosa of the upper small intestine; the rest moves to the lower small intestine where it is hydrolyzed and reconjugated in the mucosa at the $\mathrm{C}-16$ or $\mathrm{C}-3$ position with glucuronic acid. Any $\mathrm{E}_{3}-16 \mathrm{Gl}$ in the lumen is largely hydrolyzed and reconjugated in the mucosa at C-16 or C-3 position with glucuronic acid. The newly formed estriol conjugates are then transported by the blood to the kidney for excretion.

\section{ACKNOWLEDGMENT}

This work was supported in part by U. S. Public Health Service grants CA-03559 and AM-01240 from the National Institutes of Health.

\section{REFERENCES}

1. Inoue, N., A. A. Sandberg, J. B. Graham, and W. R. Slaunwhite, Jr. 1969. Studies on phenolic steroids in human subjects. VIII. Metabolism of estriol $16 \alpha$-glucosiduronate. $J$. Clin. Invest. 48: 380.

2. Goebelsmann, U., K. Sjoberg, N. Wiquist. and E. Diczfalusy. 1965. Oestriol-3-glucosiduronate, a major urinary metabolite of oestriol and oestriol-16-(17?)-glucosiduronate. Acta Endocrinol. 50: 261.

3. Stoa, K. F., and M. Levitz. 1968. Comparison of the conjugated metabolites of intravenously and intraduodenally administered oestriol. Acta Endocrinol. 57: 657.
4. Priore, R. L., and R. Y. Kirdani. 1968. Statistical analysis of data from countercurrent distribution. I. The method for estimation of the quantity and partition coefficient of each compound in the distribution. Anal. Biochem. 24: 360 .

5. Kirdani, R. Y., and R. L. Priore. 1968. Statistical analysis of data from countercurrent distribution. II. Some applications and limitations of the method. Anal. Biochem. 24: 377.

6. Sandberg, A. A., and W. R. Slaunwhite, Jr. 1965. Studies on phenolic steroids in human subjects. VII. Metabolic fate of estriol and its glucuronide. J. Clin. Invest. 44: 694.

7. Fishman, J., B. Zumoff, L. Hellman, and T. F. Gallagher. 1968. Metabolism of estriol-17 $\alpha_{-}^{-3} \mathrm{H}$ in man. Steroids. 11: 337.

8. Levitz, M., and J. Katz. 1968. The enterohepatic metabolism of estriol-3-sulfate-16-glucosiduronate in women. J. Clin. Endocrinol. Metab. 28: 862.

9. Hashimoto, Y., and M. Neeman. 1963. Isolation and characterization of estriol $16 \alpha$-glucosiduronic acid from human pregnancy urine. J. Biol. Chem. 238: 1273.

10. Slaunwhite, W. R., Jr., M. A. Lichtman, and A. A. Sandberg. 1964. Studies on phenolic steroids in human subjects. VI. Biosynthesis of estriol-glucosiduronic acid16- $\mathrm{C}^{14}$ by human liver. J. Clin. Endocrinol. Metab. 24: 638.

11. Diczfalusy, E., C. Franksson, and B. Martinsen. 1961. Oestrogen conjugation by the human intestinal tract. Acta Endocrinol. 38: 59.

12. Dahm, K., and H. Breuer. 1966. Enzymatische Untersuchungen ueber die Glucuronidieren von Oestriol beim Menschen. Z. Klin. Chem. 4: 153.

13. Emerman, S., G. H. Twombly, and M. Levitz. 1967. Biliary and urinary metabolites of estriol- $15-{ }^{3} \mathrm{H}-3-\mathrm{sul}-$ fate- ${ }^{35} \mathrm{~S}$ in women. J. Clin. Endocrinol. Metab. 27: 539.

14. Wilson, R., G. Eriksson, and E. Diczfalusy. 1964. Oestriol metabolism in pregnant women. Acta Endocrinol. 46: 525.

15. Smith, E. R., and A. E. Kellie. 1967. Oestrogen conjugates of human late pregnancy urine. Biochem. J. 104: 83.

16. Haehnel, R. 1967. The quantitative relationship of oestrogen-3-glucosiduronates and oestrogen-16(or 17)-glucosiduronates in human late pregnancy urine. J. Endocrinol. $38: 417$.

17. Dahm, K., M. Lindlau, and H. Breuer. 1967. Biogenese von Oestriol-3-monoglucuronid. Acta Endocrinol. 56: 403.

18. Maki, T., T. Sato, and T. Sato. 1962. A study on the activity of $\beta$-glucuronidase in bile in connection with precipitation of calcium bilirubinate. Tohoku J. Exp. Med. 77: 179

19. Fordtran, J. S. 1967. Speculations on the pathogenesis of diarrhea. Fed. Proc. 26: 1405.

20. Schedl, H. E., and J. A. Clifton. 1963. Cortisol absorption in man. Gastroenterology. 44: 1134.

21. Schedl, H. P. 1965. Absorption of steroid hormones from the human small intestine. J. Clin. Endocrinol. Metab. 25: 1309 .

22. Levitz, M., J. Katz, and G. H. Twombly. 1965. Biosynthesis of labeled estriol 3-sulfo-16 $\alpha$-glucosiduronate. Steroids. 6: 553.

23. Kirdani, R. Y., R. L. Priore, and A. A. Sandberg. 1968. Statistical analysis of data from countercurrent distribution. III. Biliary and urinary excretion patterns of estriol in a human subject. Steroids. 12: 215.

24. Cooper, A., D. A. Norton. and H. Hauptman. 1968. Estrogenic steroids. III. The crystal and molecular structure of estriol. Acta. Cryst. In press. 